\title{
A Profile of Digital Information Literacy Competencies of High School Students
}

\author{
Sunita Shankar, Muthu Kumar, Uma Natarajan, \\ and John G Hedberg \\ Centre for Research in Pedagogy and Practice \\ National Institute of Education, \\ Nanyang Technological University, Singapore
}

\author{
sshankar@nie.edu.sg kumarl@nie.edu.sg numa@nie.edu.sg \\ jhedberg@aces1.aces.mq.edu.au
}

\begin{abstract}
Information literacy is the ability to access, evaluate, and apply information from a variety of sources in appropriate contexts to construct knowledge. In the current digital age, information literacy has inevitably been influenced extensively by developments in technology with the emergence of digital information literacy. The Internet has become a prominent source of digital information and students need to be competent and critical users of the information hosted by the Internet. This paper describes the baseline findings of the digital curricular literacy research project undertaken by the Centre for Research in Pedagogy and Practice in Singapore. Seven Secondary schools in Singapore participated in this preliminary study. Student participants were grouped together in pairs to be collaboratively engaged in Internet information seeking tasks. The student pairs were assigned History-based and Science-based tasks and their online movements were captured using a screen capture software, Snapzpro. The findings of this study have been analyzed and will be presented in this paper based upon Ellis' information seeking behaviors model. Patterns and characteristics of students' information seeking processes were investigated according to the different stages of Ellis' model. Our findings revealed that the majority of Singapore students primarily focused on the following phases of Ellis' model: starting, browsing, chaining, differentiating and extracting. We have observed two levels of starting, differentiating and extracting which we would like to term as primary and secondary in this study. No significant trends were observed in relation to the monitoring component in his model.
\end{abstract}

Keywords: Digital Information Literacy, Information Synthesis, Knowledge Construction, Information Applications

\section{Introduction}

Information Seeking styles have changed over the past few years with the evolution of the Internet and on-line resources. This has resulted in the evolution of new learning methods and infor-

Material published as part of this journal, either on-line or in print, is copyrighted by Informing Science. Permission to make digital or paper copy of part or all of these works for personal or classroom use is granted without fee provided that the copies are not made or distributed for profit or commercial advantage AND that copies 1) bear this notice in full and 2) give the full citation on the first page. It is permissible to abstract these works so long as credit is given. To copy in all other cases or to republish or to post on a server or to redistribute to lists requires specific permission from the publisher at Publisher@InformingScience.org mation literacy strategies. This paper has evolved as part of the suite of studies for the project entitled Digital Curriculum Literacies (Freebody, Hedberg \& Guo, 2003) conducted at the Centre for Research in Pedagogy and Practice, National Institute of Education, Nanyang Technological 
University, Singapore. This paper will explore the digital Information literacy strategies and cognitive processes of these high school students. It will also to some extent illustrate the search patterns of these students.

The Digital curricular Literacies project (DCL) focuses on the key initiatives of the Singapore Ministry of Education (MOE) on the use of ICTs (Information and Communication Technologies) in school learning. The term Digital Curriculum Literacies refers to the integrated use of ICTs within the various curriculum areas. The project is a suite of three studies.

\section{The general questions of this research suite are:}

DCL I: How do teachers guide students in their ICT-related project work through their classroom interactions? How can that guidance be improved?

DCL II: How do students engage in on-line tasks? How can that be improved?

DCL III: How do students construct and craft their assessable ICT-related projects? How can the linguistic/textual and multimodal features of those outcomes be improved?

This paper comes out of DCL II study, which looked at some of the students' online usage skills. When they worked on Internet-based tasks how they navigated and searched for information, what were the strategies used and how did they integrate and synthesize information into an artifact? In a related study, (Barab, Bowdish, \& Lawless, 1997), the researchers used a multidimensional computer-based kiosk and the individuals could select the type of task undertaken thus making it difficult to determine which aspects of navigational performance resulted from the influence of the choice of tasks. This present study sought to overcome some of the limitations of these studies by utilizing a Web-based search and navigational task which was directly linked to the curriculum being taught and was not constrained by resources nor the strategies that could be employed in working with the resources.

\section{Defining Digital Information Literacy}

Doyle's (1994) has succinctly defined information literacy as the ability to access, evaluate, and use information from a variety of sources in meaningful ways. However some researchers have disagreed with such a simple and all-encompassing characterization of information literacy. From early times of its conceptualization, information literacy has been recognized to be complex and multi-faceted (Bawden, 2001). True information literacy is multi-faceted as it calls upon the combination of a rich variety of skills and knowledge (McClure, 1994; Taylor, 1986).

Tuckett (1989) breaks down this multi-faceted dimension of information literacy into a hierarchy of three levels of skills in the following ascending order of complexity:

- Simple information skills. Using a single information tool

- Compound information skills. Combining simple information skills/tools

- Complex/integrated information skills. Making use of a variety of information networks, evaluating and repackaging information

In the current digital age, information literacy has inevitably been influenced extensively by developments in technology. Thus the term digital literacy or digital information literacy has emerged prominently. Digital information literacy can be defined as the ability to understand and use information in multiple formats from a wide variety of networked computer sources and it involves the skill of deciphering multimedia images, sounds and text (Gilster, 1997; Lanham, 1995). However Gilster emphasizes that digital literacy should not be confused with computer/IT literacy. Information literacy and computer literacy are distinct but interrelated concepts. The former has to do with content and communication whilst the latter deals with technology infra- 
structure (Lynch, 1998; Tuckett, 1989). The digital environment is multifaceted and open- ended providing a plethora of information to the learner in numerous modes and is a cognitive tool enhancing 'self directed' and 'exploratory learning'. However, this digital environment does face some challenges as far as the extent of 'self directed' learning and the amount of mediation and scaffolding required during a task.

\section{Information Seeking and Analysis Models}

Many conceptual models on information seeking and analysis have been developed in recent years due to the expanded interest in this field of research. Earlier models on information retrieval focused on the representation, storage and systematic retrieval of information or on information systems. However the current view of information seeking and analysis emphasizes understanding, reflection and communication based upon the needs, characteristics and actions of information seekers (Dervin \& Nilan, 1986). This has been in tandem with progress made in cognitive psychology. In information seeking there is always a need to solve a problem. According to Chi and Glaster (1985) "A problem is a situation in which you are trying to reach some goal, and must find a means for getting there". Psychologists Howard (1983), Mayer (1983) and Wickelgren (1974) have observed three characteristics common to all problems. First there is an 'initial stage' from which the problem solver starts. Then there is a 'goal state' that the information seeker wishes to achieve and is different from the initial state. Third, there is 'operations' that are performed in the initial stage to achieve the goal state. Ellis' Information-Seeking Behaviors Model (1989) is used in this paper as the framework to analyze in-depth. Although Ellis' model of information seeking was developed for a non-digital environment this model has been chosen for analysis as it has been developed according to the theories of cognitive psychologists. The different phases in this model can capture the different cognitive processes of the students when navigating for information on-line. Several other newer models were reviewed which evaluate different aspects of thinking and navigation during digital information seeking. Ellis' model was chosen as it is unique and suitable for the measurement of cognitive processes that are in line with the studies of psychologists Howard, Mayer and Wickelgren. All theories do not have to develop for the current situations. Older theories can be revisited and adapted to new situations. Dewey's theories of education was developed several years ago but are still used by educationists as a reference point for pedagogical issues. Similarly Bloom's taxonomy had been developed some time ago and although modified by Anderson and Krathwohl (2001) is still the basis of the taxonomy of modern learning. Ellis' model can be adapted to the on-line environment with a few modifications, which we have described in this paper. We have included primary and secondary levels of starting, differentiating and extracting. Also Ellis' model has been very recently revisited and used to model the information seeking behavior of social scientists from 14 different countries. Based on the study they developed a new model which grouped the information seeking features into four inter related stages - searching, accessing, processing and ending (Lokman, \& Tibbo, 2003). Thus although Ellis' model is relatively old it is still being used and revisited by researchers who are analyzing information seeking behaviors in the modern multi-faceted digital environment.

\section{Ellis' Information-Seeking Behaviors Model:}

Ellis (1989) proposed and elaborated on a general model of information seeking behaviors based on studies of information seeking patterns. The model describes six categories of information seeking activities: starting, chaining, browsing, differentiating, monitoring and extracting. Starting can be categorized as the 'initial state' and chaining, browsing, differentiating, monitoring and extracting as the 'operations' to achieve the 'goal' which is synthesis of the information and generation of knowledge in the form of an artifact. In order to make goals more precise the in- 
formation seeker needs more knowledge. According to Doerner (1982) this is possible by changing 3 ways of reality into knowledge of that area.

(a) Information gathering by questioning and reading, (b) Forming analogies (c) application of abstract schemata. A fourth component which is also important is knowing when to stop acquiring knowledge and to start acting. This component can be thought to be an aspect of Metacognition (Jousovec, 1994). According to Getzels and Smilansky (1983) problem formulation initiates thought towards solution. Wertheimer (1945) mentioned:

"The function of thinking is not just solving an actual problem but discovering, envisaging, going into deeper questions. Often in great discoveries the most important thing is that a certain question is found. Envisaging, putting the productive question is often more important, often a greater achievement than the solution of a set of questions".

A more elaborate problem construction model has been defined recently by Mumford, Palmon and Redmond (1994) called problem construction and defined it as a process which defined the goals, objectives and parameters of the problem-solving effort. They argued that an effective problem construction may have an impact on the operation of the multiple, subordinate processes and thus the success of creative problem solving.

Ellis' model of information seeking and processing is described below. The 'Starting' stage of Ellis' model has the maximum impact on the other operational phases of the model and plays a substantially important role in the creative problem solving process of information seeking and knowledge generation.

1) Starting: Those activities that form the initial search for information - identifying sources of interest that could serve as starting points of the search

2) Chaining: Following up activities on references from a particular article or other forms of referential connection between materials. Chaining can be backward or forward.

Backward chaining takes place when pointers or references from an initial source are followed and forward chaining identifies and follows up on other sources that refer to an initial source or document.

3) Browsing: The activity of semi-directed search in areas of potential search. The individual often browses by looking through tables of contents, lists of titles, subject headings, names of organizations or persons, abstracts and summaries and so on.

4) Differentiating: In this activity, the individual filters and selects from among the sources scanned by noticing differences between the nature and quality of the information offered. The differentiation process is likely to depend on the individual's prior or initial experiences with the sources, word-of-mouth recommendations from personal contacts or reviews in published sources.

5) Monitoring: The activity of being aware of developments in an area by following up regularly on particular sources. The individual monitors by concentrating on a small number of what are perceived to be core sources.

6) Extracting: The activity of systematically working through a particular source or sources in order to identify material of interest. Extracting may be achieved by consulting the source, or indirectly by looking through bibliographies, indexes, or online databases.

Ellis' (1989) model can be applied in the context of electronic hyperlinked systems such as the World Wide Web (Barajas \& Higueras, 2003). An individual could possibly begin his or her search from one of a few favorite starting pages or sites (starting); follow hyper textual links to navigate backwards and forwards through the WebPages (chaining); scan the contents of the Web pages of the sources (browsing); bookmark useful sources for the purpose of future visits (differ- 
entiating); subscribe to services that alert users through emails of new information or developments (monitoring); and search to extract meaningful information from a particular site (extracting).

\section{Methodology}

\section{Data Collection and Participants}

The DCL II study collected and analyzed data in two major phases. Seven Secondary schools in Singapore participated in the DCL II project. The study aimed to document, among other things, the navigational and search patterns of Secondary 1 school students while they worked in an online environment using the Internet on curriculum-related tasks in History and Science. Student participants were grouped together in pairs to be collaboratively engaged in the tasks. Their online movements were tracked using screen-capture software SnapzPro. The students were exposed to an open environment, the Internet to search for information to complete the task. This experiment followed the constructivist theory of giving the students task on topics they have already been taught earlier in class (Jonassen, 1991). This study analyzed the different cognitive process of the students.

\section{The Tasks}

\section{History Task: Early Civilisations}

Select 1 set only.

For each task you will have access to the following Search Engines in the BookMark Bar: Google (also in the main bar); www.google.com; Ask Jeeves www.ask.com; Mamma.com www.mamma.com; Yahoo www.yahoo.com but you may select another search engine

\section{Unit: Early civilisations}

Based on what you have learned about the factors which led to the rise of early civilisations (like suitability of climate and closeness to water), do an Internet-search for one set of the early civilisations:

\section{Set one: Mesopotamia and Sri Vijaya}

What similarities and differences can you see in these civilisations compared to the factors you've studied?

Showcase your findings using a graphic organiser (e.g., chart, table, diagram) to give concrete support for each of the features identified. You might care to use MS Word or PowerPoint.

\section{OR}

\section{Set Two: Egypt and Greece}

What similarities and differences can you see in these civilisations compared to the factors you've studied?

Showcase your findings using a graphic organiser (e.g., chart, table, diagram) to give concrete support for each of the features identified. You might care to use MS Word or PowerPoint

\section{Science Tasks}

\section{Select 1 topic only.}


For each task you will have access to the following Search Engines in the BookMark Bar: Google (also in the main bar); www.google.com; Ask Jeeves www.ask.com; Mamma.com www.mamma.com; Yahoo www.yahoo.com but you may select another own search engine

\section{Topic 1: Measuring length}

You may have learned how the vernier calipers, (and micrometer screw gauge) are used to measure length.

Do an Internet search to find out the industrial applications of these instruments.

Illustrate the range of examples by collecting resources and summarise the examples in a paragraph. You might care to use MS Word or PowerPoint.

\section{OR}

\section{Topic 2: Cells}

You may have learned about plant and animal cells, and how to use the microscope to study the structure of cells.

Do an Internet search to find out the important historical events about scientific discoveries of cell structures.

Prepare a time line with marked intervals that visually represents the units of time and the sequence of the events that took place.

Include dates, discoveries, names of scientists and their origins, and other relevant information.

Illustrate the range of examples by collecting resources and summarise the examples in a paragraph. You might care to use MS Word or PowerPoint.

\section{Data Analysis}

For this paper we analyzed a random sample of students who participated in the baseline study (Phase 1). This data was analyzed qualitatively with content analysis following Ellis' Model on information searching processes. A few examples of the student's searching processes are illustrated in this paper.

\section{Discussion}

Descriptive content analysis of some of the videos of the students has led to the identification of the different information-seeking behaviors based on Ellis' model. The processes concur with the theories of some cognitive psychologists. A couple of new patterns within the stages of Ellis' model emerged in this study.

A familiar "Starting" by most of the students was with the prescribed search engines (Google, Yahoo, Mamma, Ask Jeeves). They used short sentences, varying from a keyword to a phrase, to search for information from the search engines. They did not search for popular websites directly from the browser. Majority of the students used phrases picked from the task instructions for their searches. Some examples of the sentences they used are: 'Industrial uses of vernier calipers', 'how industries make use of vernier calipers', 'ancient greek civilisation' 'occupation of ancient egypt', engineering “vernier caliper", "vernier caliper" manufacturing etc. However they were normally critical while selecting from this information. The students' 'Starting' process indicated that they were limitedly exploring for information as they derived most of the search phrases and keywords from the task. They were focused in solving the immediate problem by using the keywords and phrases from the task. They did not explore the wide-open arena of information available on the Internet by using deeper questions in their 'starting' or 'initial state' of information 
search. As mentioned by Weitheimer (1945) often by deeper questioning more discoveries are made which is important for the development of higher order thinking and successful problem solving. The students did not explore indirect questions related to their task, which would have given them a broader view of the topic. This would have helped them in their decision to synthesize the information to complete the task. However, information seeking process is a difficult task and most students experience different levels of uncertainty during the process (Kuhlthau, 1993). This uncertainty may have increased in the open environment of the Internet compared to the traditional information seeking environment of text books and hard copy resources. Thus some students tended to use the task as a guideline for the search, which restricted their information seeking exploration. We would like to call this 'primary starting'. 'Secondary starting' as more complex and deeper questioning in the form of search terms. They were active searchers and had an immediate goal in their search. They were focused on their goal and did not click into many websites. Most students did not use Boolean operators and advance search strategies to narrow down the searches. In fact, even in a basic search, their searches were very broad. For example 'Egypt', 'ancient greek civilization, 'about greek civilisation' vernier calipers'

Their 'starting' process to a large extent determined their operational process and their goal achievement. According to Ellis' model they were actively 'browsing' for information. They spent most of their time browsing the result page and the source page. Typically one of the following types of processes were observed subsequently after a "Start",

a) The pupils continued the search and went into the next stage, 'Browsing' into the result page and/or the source page (or)

b) The pupils typed a new set of words in the existing search engine to "Start" a new search - this happened when they were not satisfied with the information they found on the results page and/or source page (or)

c) The pupils opened up a new search engine to "Start" a new search.

"Differentiating" was observed in the search process of the participants. According to Ellis' model, differentiation is when "the individual filters and selects from among the sources scanned by noticing differences between the nature and quality of the information offered" (Ellis, 1989). They scanned through the page of hits in many situations and appeared like they were reading the abstracts. Since they were working in pairs, they discussed with each other on the appropriate choice. In most cases they did not automatically click on the first hit which is supposed to be a common trend with most novice information searchers. They seemed to be engaged in the cognitive processes of critical thinking and decision making before clicking on any hit after a search. They scanned and read through the abstracts of the first hit page. It seemed that in the beginning the students were uncertain on information seeking strategies for the topic. After working on the search process for sometime, they were more optimistic, although still confused after they were encountered with a lot of information of the Internet. Critical thinking and decision-making are aspects of differentiation. However differentiation was not observed from different perspectives. Students were able to differentiate information only according to relevance. They did not have any specific preference of domains e.g. edu, com, net. They selected information from sites according to the relevance of the information to the task. Examples of some sites they visited www.estudentservices.com, http://ancienthistory.about.com, www.emuseum.mnsm.edu/prehistory, www.topics.com, www.fordham.edu, www.martindalecenter.com, http://history1900.about.com, www.tntech.edu, http://ch5.semo.edu , http://phoenix.phys.clemson.edu, www.cellalive.com . They were not differentiating the information according to authority and accuracy by comparing the same information with different sources and studying more in detail the credentials of the author. They did not look for any kind of biases in the information. We have decided to call this action "Primary differentiation": which 
is choosing the relevant websites from the results page." Secondary Differentiation" is more complex where the participants should select information according to a combination of relevance, accuracy and authority and by comparing and contrasting different points of views and biases from a variety of sources. Primary differentiation is commonly seen in most student populations. Since this is an analysis of the baseline data, we hope to see "Secondary Differentiation" by the students in the post-intervention data. "Chaining" as described in Ellis' model was observed to some extent among these students. They also tried 'related sites' where they were quite successful to get relevant information. This move according to Ellis' model is 'forward chaining' During some searches the students search patterns were quite non-linear as they went into links and sub-links which according to Ellis' model is 'backward chaining' However, they were able to come back to the original search page if they were not satisfied with the information . Most students emphasized on the relevance of information to their research question. Returning to a bookmarked source was also not observed, hence there was an absence of the "Monitoring" step as described in Ellis Model. "Extraction" or saving the web information as another Word or Power point file to construct an answer to the task given was attempted in many cases. Typically, after a few "Starts" and "Browses", the pupils extracted information from a source on the web which they found noticeably relevant and pasted it on to a word or power point document which was incomplete in many cases. However, it was noticed that most students gathered many images from the web pages and combined it with the text to make meaning. They used multimodality in their artifacts. This made their on-line search process more complex than traditional information seeking from the text-book. We would thus like to term this as "Primary Extraction". Referring back to Dervin \& Nilan's work mentioned earlier, with sufficiently more time for understanding and reflection, we hope the students would advance to the "Secondary Extraction" stage where more synthesis of the information would take place and they would extract meaningful information to complete the tasks given to them.

To emphasize the above points, an example of the information seeking processes of a pair of students during one search will be illustrated and explained according to Ellis' model. Both groups of students worked on the same history task.

\section{Task}

Based on what you have learned about the factors, which led to the rise of early civilisations (like suitability of climate and closeness to water), do an Internet-search for one set of the early civilisations:

\section{Set Two: Egypt and Greece}

What similarities and differences can you see in these civilisations compared to the factors you've studied?

Showcase your findings using a graphic organiser (e.g., chart, table, diagram) to give concrete support for each of the features identified. You might care to use MS Word or PowerPoint

Example 1: Group 1 (Figure 1): They started with the keyword 'Egypt' by using the search engine 'Yahoo'. After browsing through half the result page slowly they clicked result \# 4. They entered and selected www.us.sis.gov.sg an e- Islamic museum environment. They scanned the full page and then did a lot of 'backward chaining' in this search. They first clicked the weapons hall, and then moved back to the museum home page. They then scanned the Pottery hall and again moved back to the museum home page. They then started a new search using 'Ask Jeeves'. In this search there was starting, browsing, 'primary' differentiation and backward chaining. However, extraction and monitoring was not present. 


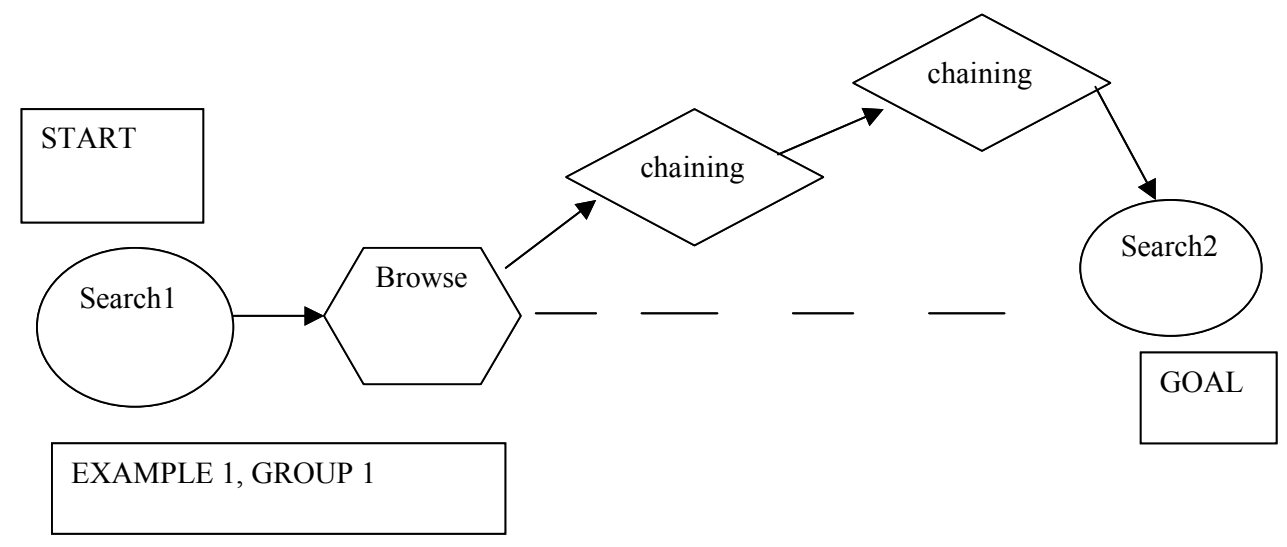

Figure 1. Example 1, Group 1

Example 2: Group 2: (Figure 2) They started by using the phrase 'Ancient Greek Civilization' on Yahoo and clicked hit \# 3 based on relevance of the information to the task. The students browsed and extracted images and pasted them into power point in a collage format to construct meaning. They alternated between extracting images and browsing pages. Then they did 'backward chaining' by clicking on the link 'Minoans' and extracted more images and arranged them into different slides with titles. The students organized the information according to different headings in each slide. 1. The ancient Greek Civilization 2. The birthplace of Greece 3.'Minoan Palace and the Pyramids'. In this particular search there was a little 'starting' and 'primary differentiation', a lot of 'browsing' and some 'primary extraction'. 'Monitoring' and book marking of sites was not observed at all.

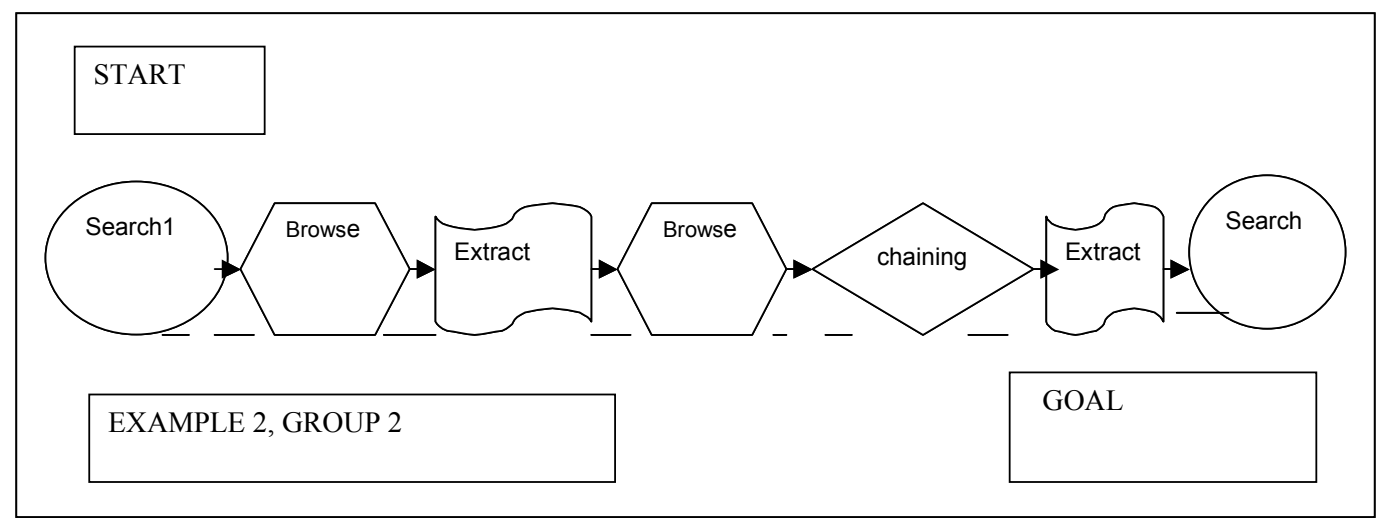

Figure 2. Example 2, Group 2

\section{Conclusion}

This study revealed that the majority of Singapore students primarily focused on the following phases of Ellis' model: starting, browsing, chaining, differentiating and extraction. However, starting was not very exploratory but was very much guided by the task terms, which we have termed 'primary' level starting. Their search terms were not deep enough to generate information with a broader perspective. We have also observed two levels of differentiation and extraction, which we have termed as primary level and secondary level in this study. We have categorized the extraction in this way since we felt that with more time for understanding and reflection, the 
students would advance to Secondary Extraction and also complete the tasks given to them. No significant trends were observed in relation to the monitoring component in his model.

\section{A Case Study: Online Navigation of a Pair of Students}

This case study describes the pair of student's complete information search process.

The students first start by clicking on Yahoo to do a search. This is followed by chaining where they go back and forth accessing the results displayed by the search engine. Then the students conducted another search with search term reformulation. Results were displayed though students choose instead to initiate another search operation with a different search term. The first result is accessed and students browse the content. Chaining takes place next with an embedded link being clicked and more browsing. Then a new search is initiated with a different search engine and forward chaining takes place with one of the results being accessed. Then backward chaining with new search term being entered for query reformulation. Results displayed are browsed. The $3^{\text {rd }}$ result is accessed through forward chaining. Browsing of the content followed by backward chaining back to root search engine page and then a new search term is entered. $1^{\text {st }}$ result is accessed through forward chaining and this is followed by browsing of content. 'Back' button is clicked to trigger backward chaining to go back to listings page. Further browsing of listings is observed. $5^{\text {th }}$ result is accessed through forward chaining and browsing of content takes place. Next 'back' button is hit to enforce backward chaining and a new search term is reentered to start a new search operation. One of the links is next clicked to navigate forward and content is browsed. Then students navigate backwards to search results page and the next 10 results page is accessed where the first listing is then chosen. Twice the 'back' button is clicked to traverse backwards to browse the original results. The next 10 results page is then accessed (forward chaining) to access $2^{\text {nd }}$ result and content is browsed. Then backward chaining is done again by clicking 'back' button. A new search started with search term reformulation and subsequently forward chaining is executed by clicking on the first result where the web content is browsed followed by backward chaining. Next forward chaining takes place with $3^{\text {rd }}$ result being accessed and then the ensuing action of browsing to read the content found in the website.

In summary, this pair of students mostly engaged in the activities of primary starting, chaining and browsing with differentiating, monitoring and extracting being completely absent in their attempts at completing the information problem-solving task. As a result no artifacts were submitted and thus the students were not successful in accomplishing the given task. Figure 3 represents the information-seeking behavior of the Case Study pair. 


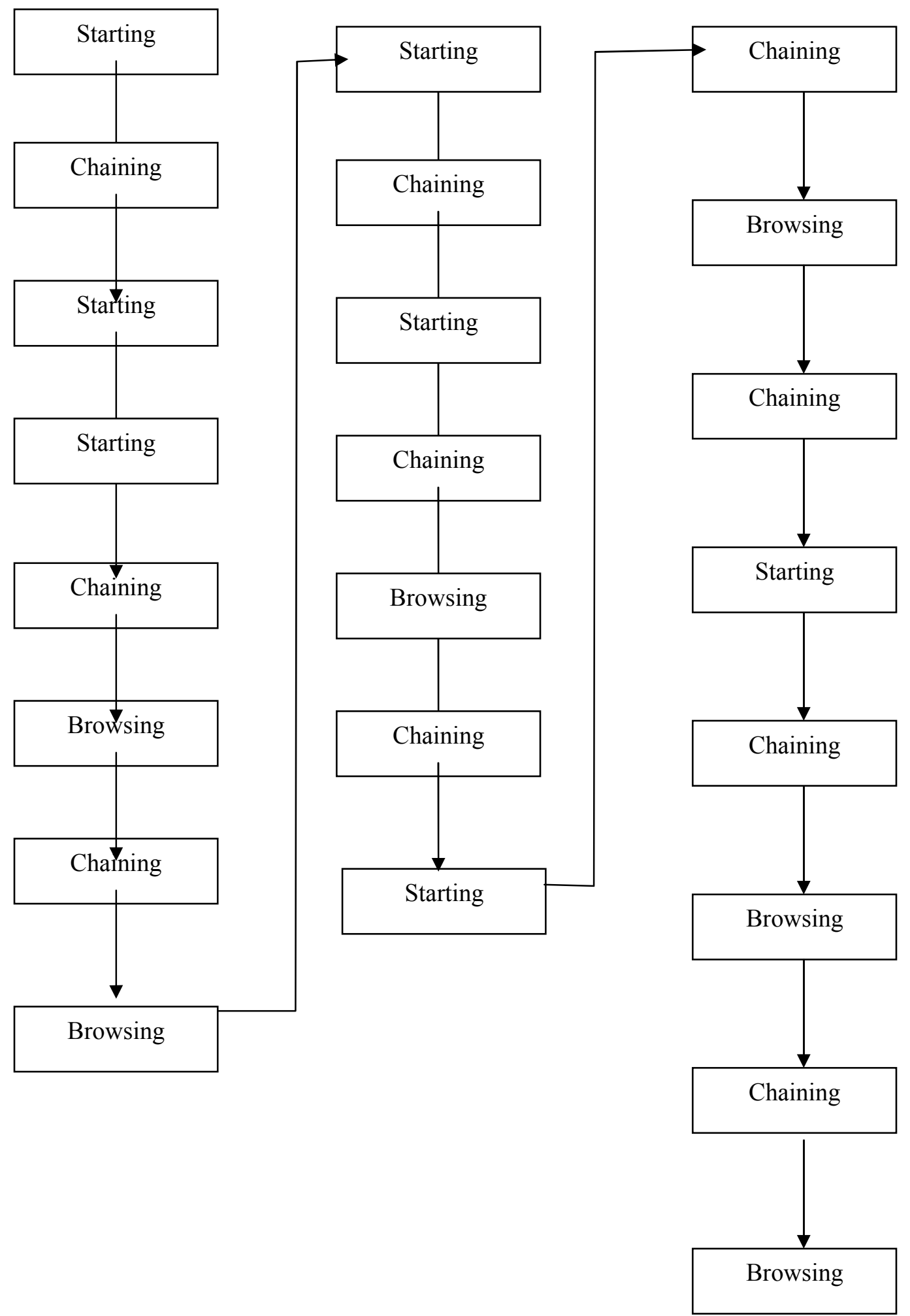

Figure 3. Information-Seeking Behavior of the Case Study Pair 


\section{References}

Anderson, L.W., \& Krathwohl (Eds.). (2001). A Taxonomy for Learning, Teaching, and Assessing: A Revision of Bloom's Taxonomy of Educational Objectives. New York: Longman.

Barab, S. A., Bowdish, B. E. \& Lawless, K. A. (1997). Hypermedia navigation: Profiles of hypermedia users. Educational Technology Research and development, 45 (3), 23-41.

Barajas, M., \& Higueras, E. (2003). Initial taxanomy of information seeking behaviours. Retrieved from www.ub.es/euelearning/seeks/FINAL\%20VERSION\%20UB_DEL3.pdf

Bawden, D. (2001). Information and digital literacies: A review of concepts. Journal of Documentation, 57 (2), 218-260.

Chi, M. T. H, \& Glaser, R (1985). Problem solving ability. In R. J. Sternberg (Ed.), Human abilities: An information processing approach. New York: Freeman.

Choo, C. W., Detlor, B., \& Turnbull, D. (2000). Information seeking on the Web: An integrated model of browsing and searching. Available: http://firstmonday.org/issues/issue5_2/choo/index.html

Dervin, B., \& Nilan, M. (1986). Information needs and uses. New York: Knowledge Industries.

Doerner, D. (1982). Lerner des wissens und komptenzerwerbes. [Learning of knowledge and competency]. In B. Trieber \& F. E. Weinert (Ed.), Teaching and learning research. Muenchen: Urban.

Ellis, D. (1989). A behavioural model for information retrieval system design. Journal of Information Science, 15, 237-247.

Getzels, J. W. \& Smilansky, J. (1983). Individual differences in pupil perception of school problems. British Journal of Educational Psychology, 53, 307-316.

Gilster, P. (1997). Digital literacy. New York: Wiley.

Howard, D.V. (1983). Cognitive psychology. New York: Macmillan.

Jausovec, N. (1994). Flexible thinking: An explanation for individual differences in ability. New Jersey: Hampton.

Jonassen, D. H. (1991). Evaluating constructivist learning. Educational Technology, 31, 28-33.

Kuhlthau, C. C. (1993). A principle of uncertainty for information seeking. Journal of Documentation, 49 (4), 339-355.

Lanham, R. A. (1995). Digital literacy. Scientific American, 272 (3), 160-161.

Lokman, I. M. \& Tibbo, H. R. (2003). Modelling the information seeking behavior of Social Scientists: Ellis's study revisited. Journal of the American Society for Information Science and Technology, 54 (6), 570-587.

Lynch, C. (1998). Information literacy and information technology literacy: New components in the curriculum for a digital culture: Committee on Information Technology Literacy.

Mayer, R. E. (1983). Thinking, problem solving, cognition. New York: Freeman.

McClure, C. R. (1994). Network literacy: A role for libraries. Information Technology and Libraries, 13, $115-125$.

Mumford, M. D., Palmon, R. R., \& Redmond, M. R. (1994). Problem construction and cognition: Applying problem representations in ill-defined domains. In M.A. Runco (Ed.), Problem finding, problem solving and creativity. Norwood, NJ: Ablex.

Taylor, R. S. (1986). Value-added processes in information systems. Norwood, NJ: Ablex Publishing.

Tuckett, H. W. (1989). Computer literacy, information literacy and the role of the instruction librarian in coping with information illiteracy: Bibliographic instruction for the information age. Ann Arbor MI: Pieran Press. 
Wickelgreen, W. A. (1974). How to solve problems: Elements of a theory of problem solving. San Francisco, CA: Freeman.

\section{Biographies}

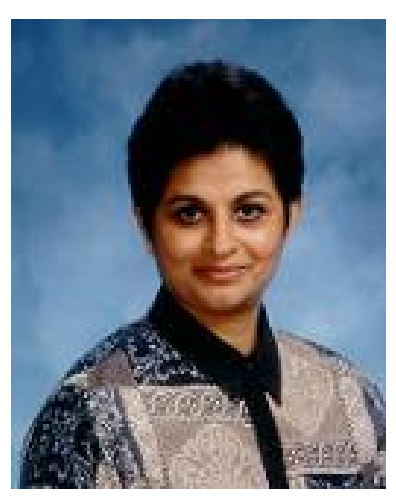

Sunita Shankar is currently a Research Associate at the Centre for Research in Pedagogy and Practice, National Institute of Education, which is a part of the Nanyang Technological University, Singapore. She is presently involved with research projects funded by the Ministry of Education. Sunita completed her undergraduate studies in Social Sciences and Education from Calcutta University, India and her Masters in Library and Information Management from the University of Wales, Aberystwyth (UWA), U.K. Her research interests are in the areas of information literacy, learning sciences and cognitive learning tools, with a special emphasis on technology, language and cognitive flexibility.

Sunita has co-authored papers on digital literacy based on empirical findings from her research in Singapore over the last year. These papers will be presented at various international conferences this summer in the U.S.A., Canada and Singapore. She is authoring a chapter in an academic book titled 'Reforming learning: Issues, Concepts and Practices in the Asia Pacific Region' to be published in 2005/2006. She has also contributed to other publications, and is a member of the international board of reviewers for Informing Science Journal, Journal for IT Education and Journal for Knowledge and Learning objects.

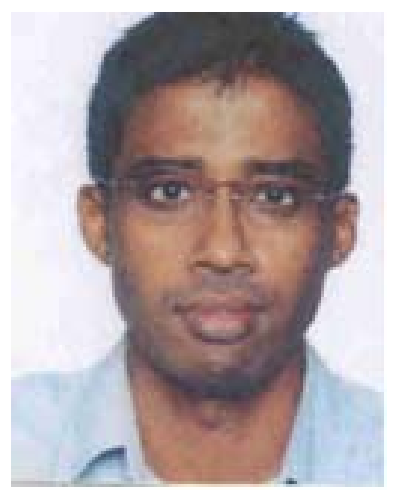

Muthu Kumar, having obtained his Bachelors in Engineering (Civil), completed his Postgraduate Diploma in Education at the National Institute of Education specializing in the subjects of Mathematics and Physics. He has extensive teaching experience in schools in Singapore and has also worked as an educational technologist. Currently he is an instructional designer with the Centre for Research in Pedagogy and Practice at the National Institute of Education, Nanyang Technological University, Singapore. His areas of research interest include e-learning design frameworks and factors that impact these frameworks, multimedia design and its cognitive implications as well as knowledge management technology. 


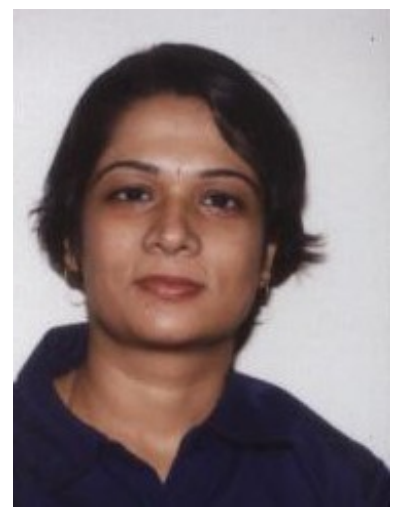

Uma Natarajan started her career in India as a research chemist with a pharmaceutical company after obtaining a Masters in Chemistry. Subsequently she completed her Masters in Education with a study of psychology and sociology in the field of education and taught physical sciences at secondary school level. Moving to Singapore in 2000, she began consulting a number of schools in Singapore to integrate ICT (Information \& Communication Technology) in education and helped them build digital repositories. She is currently a Research Associate at the Centre for Research in Pedagogy \& Practice at National Institute of Education, NTU, Singapore.Her research interests include Digital Repositories, e-learning, teacher education and the integration of ICT in Science education.

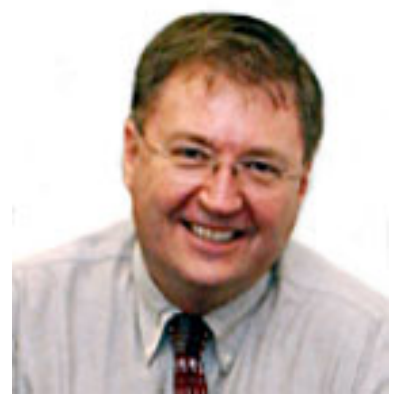

Dr. John Hedberg is currently the Editor-in-Chief of Educational Media International, published by Taylor and Francis London, a refereed journal for those interested in the application of media and technology in learning contexts throughout the world. He currently serves on the Editorial Advisory Boards of the Journal of Interactive Learning Research, ALT-J and Distance Education. His teaching and research interests focus upon cognitive strategies, interface design for learning with information and communications technologies, and implementation and evaluation of technology based learning. He has also written widely on policy aspects of new technologies in education.

He also has been a professional video producer and designed open and distance learning programs. He was the executive producer for the Australia on CD project "StageStruck: Theatre Interactive" which won a number of multimedia awards including the 1998 Gold EMMA (European Multimedia Award) and the 1998 BAFTA (British Academy of Film and Television Arts) Interactive Treatment award. He was formerly Professor of Education and Director of emlab (educational media laboratory) at the University of Wollongong. He was also for many years the Associate Dean of the Faculty of Education and Head of the Graduate School of Education at the University of Wollongong.

From January 2004, he is also half-time in the Instructional Sciences AG, developing their research infrastructure and research supervision. 